\title{
Creating Measurable, Practice-Relevant Day-1 Competencies for Swine Veterinary Education
}

\author{
Perle E. Zhitnitskiy, Thomas W. Molitor, Montserrat Torremorell, Laura K. Molgaard \\ Department of Veterinary Population Medicine, College of Veterinary Medicine, University of Minnesota, Saint Paul, Minnesota, USA
}

\section{Abstract}

Background: Veterinary education (VE) is increasingly transitioning toward a competency-based model with a focus on educational outcomes. The American Association of Veterinary Medical Colleges published a framework of competencybased veterinary education (CBVE) to provide guidance to veterinary educators in creating a curriculum that would graduate proficient veterinarians, capable of carrying out activities central to the profession, without supervision. Aims and Objectives: Swine Faculty at a Midwest Institution aimed to create a subset of competencies anchored in the CBVE framework for graduates aspiring to practice swine medicine. Methods: Using the Delphi process and the collaboration of swine practitioners and educators around the country, the team developed a list of 109 competencies divided into nine domains and three levels of expertise. Results: The list was designed as an online, interactive, savable tool, available at http://z.umn.edu/SwineCompetencies. Conclusion: Following this work, the swine faculty plans to evaluate the swine curriculum at the college level with the intent to incorporate additional opportunities for the students to practice and be assessed on the activities listed.

Keywords: Competency, education, medical, swine, veterinary

\section{INTRODUCTION}

Veterinary education (VE) is transitioning toward a competency-based model with a focus on educational outcomes. This means that in addition to teaching and assessing scientific knowledge and facts, veterinary students need opportunities to learn and practice the competencies (which integrate knowledge, skills, values, and attitudes) that they will be using when they graduate and start practicing. ${ }^{[1,2]}$ Indeed, Welsh et al. define a Day-1 competency as one that the new graduate is expected to perform on graduation without any supervision from qualified staff. ${ }^{[3]}$ Competencies and the skills they include can be widely applicable across members of the same profession or be more specific to a branch of the profession, in this case, a focus on a certain animal species. The latter is more readily identifiable, and this is why the first efforts to define skills in VE originated from species-specific practitioners. Indeed, some of the first attempts to define skills necessary for a veterinary graduate were made by small animal veterinarians in Australia ${ }^{[4]}$ and by food animal veterinarians in the US. ${ }^{[5]}$ The American Association of Equine Practitioners created a list of core competencies for graduates interested in equine practice. ${ }^{[6]}$

\begin{tabular}{|l|l|}
\hline \multicolumn{3}{c|}{ Access this article online } \\
\hline Quick Response Code: & \multicolumn{1}{|c|}{ Website: } \\
& www.ehpjournal.com \\
\cline { 2 - 2 } & \\
\end{tabular}

More recently, broad competency frameworks have been developed in health professions such as human and veterinary medicine. ${ }^{[7-10]}$ In 2018 , the Association of American Veterinary Medical Colleges Competency-Based veterinary education (CBVE) Working Group published a document outlining the framework of competencies to be used by educators and colleges to guide the development of competency-based curricula and assessments. The document entitled "CBVE: Part 1 - CBVE Framework is organized into nine domains: (1) clinical reasoning and decision-making, (2) individual animal care, (3) animal population care, (4) public health, (5) communication, (6) collaboration, (7) professionalism, (8) financial and practice management, and (9) scholarship. There are 32 competencies in all, organized under the nine domains, and each competency is illustrated by example subcompetencies (with more specificity than the competencies). ${ }^{[9]}$ Delineating competencies enable all

Address for correspondence: Dr. Perle E. Zhitnitskiy, College of Veterinary Medicine, University of Minnesota, AS/VM 385J, 1988 Fitch Ave, Saint Paul, Minnesota, 55108, USA. E-mail: pboyer@umn.edu

This is an open access journal, and articles are distributed under the terms of the Creative Commons Attribution-NonCommercial-ShareAlike 4.0 License, which allows others to remix, tweak, and build upon the work non-commercially, as long as appropriate credit is given and the new creations are licensed under the identical terms.

For reprints contact: reprints@medknow.com

How to cite this article: Zhitnitskiy PE, Molitor TW, Torremorell M, Molgaard LK. Creating measurable, practice-relevant day-1 competencies for swine veterinary education. Educ Health Prof 2019;2:59-64. 
stakeholders (e.g., faculty, veterinarian mentors, veterinary technicians, and veterinary students) to work toward the common goal of ensuring that the graduates are competent in all of the domains required for Day-1 practice as a veterinarian. It also can support students to take a more active approach in their training. ${ }^{[3,7]}$

By giving students access to a list of Day-1 competencies, they will be able to identify on their own and with guidance from advisors and mentors, areas in which they need additional training to practice without supervision after graduation. To achieve this goal, competencies must be well defined and described with clarity. Previous work ${ }^{[3]}$ has shown that it is important to define the competencies and the skills they contain in a precise manner so that students can readily identify and understand what activities are expected from them and how they may relate to each other. In addition, a precise articulation of competencies helps faculty members develop appropriate and useful methods to assess the level of proficiency expected from students.

It is important to underline that the taxonomy surrounding competencies in the context of VE has been variable. The current literature adopts the medical education definition of "an observable ability of a health professional related to a specific activity that integrates knowledge, skills, values, and attitudes." ${ }^{[2]}$ In this more recent definition, the authors emphasize the importance for a competency to be multifaceted and to incorporate more than just the physical, "hands-on" aspect that could then be described as a skill.

The objective of this project was to design Day-1 competencies that are adapted to swine veterinary practice and that are practical, measurable, and incorporable into a veterinary curriculum. The swine competencies could be described as subcompetencies, in that they are more specific than the broader CBVE competencies and have been mapped to those competencies. For the purpose here and for everyday conversation among veterinary educators, they have been labeled as Day-1 swine competencies.

\section{Methods}

The Day-1 competencies for swine-interested veterinary graduates were developed by following the Delphi process, which consists in developing an initial and provisional document, to send it to topic experts for evaluation and to revise the document based on the expert's feedback. ${ }^{[1]}$ This methodology has been a common way to create professional veterinary competencies for the past 15 years. ${ }^{[3,5,12,13]}$ Across the literature, experts included in the discussion of the initial competency list were most often practitioners, but sometimes, specialty clinicians at teaching colleges, ${ }^{[3]}$ young Doctor of Veterinary Medicine (DVM) graduates, and DVM students ${ }^{[13]}$ were also consulted. In the project presented here, practitioners and teaching faculty were recruited to participate.

The objective of the project was to develop a list of Day-1 swine veterinary competencies that are practice relevant and easily referenced by DVM students.

Five consecutives steps were followed to reach this objective [Figure 1].

Step 1: The first step was to create a provisional list of competencies that DVM students should be proficient at upon graduation. A group of seven faculties specialized in swine health and production with a significant involvement in teaching DVM students volunteered to be part of the focus group who would create the first version of the list. To do so, one of the faculty members applied for and received an award from the American Association of Swine Veterinarians (AASV) Foundation partly to hire a student intern to help with the project. After searching the literature and compiling older versions of swine skill lists from three separate universities, two from the Midwest and one from the East coast, a first document was created. Syllabi of swine-related courses and more particularly senior clinical rotations were compared to the skill list to ensure that swine-related activities taught during the DVM curriculum would not be overlooked.

Each of the activities mentioned was then evaluated to ensure that they were measurable. The reviewers asked themselves "Can we design a type of assessment in which a student could demonstrate to us that they can perform this skill?" This first triage allowed for the removal of knowledge-based learning objectives, which, although necessary to develop a swine curriculum, could not be considered as competencies which integrate both knowledge and skill. In addition, some competencies were reworded to ensure relevance to today's practice of swine medicine; some also needed to be made more specific to be understood by students and to avoid confusion as to what the expectations were.

Step 2: The second step of the process was to enroll experts in swine medicine practice. A task force of six swine practitioners and two swine faculty members from other colleges was assembled. The experts were selected based on their familiarity with modern swine veterinary practice, how often they hosted DVM students for internships or externships, and if they had hired new DVM graduates recently. Swine practitioners were

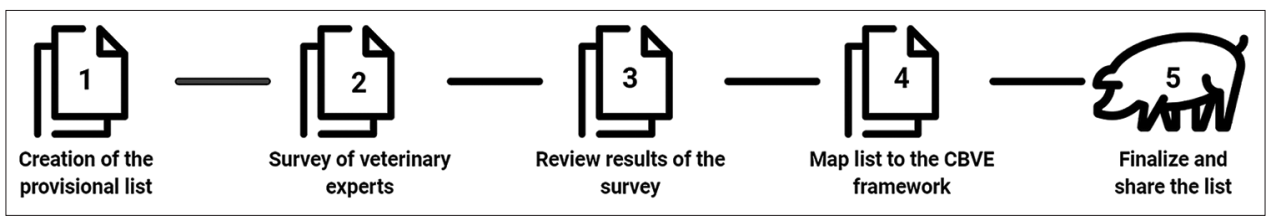

Figure 1: Steps undertaken to develop and refine the Day-1 swine veterinary competencies 
selected from both the Midwest and the East Coast which are the areas with the highest swine density in the United States. Faculty members included in the panel were faculty advisors from the AASV in their respective colleges of veterinary medicine. All of them had a comprehensive understanding of the swine curriculum taught at their institutions and were involved in teaching DVM students.

Each member received the list of skills and competencies created in Step 1 with the instruction to assign them a score based on the level of expertise required at graduation [Figure 2]:

- $\quad$ Score 1 = Basic competency: Every DVM graduate should be able to perform this activity

- $\quad$ Score 2 = Intermediate competency: Every DVM graduate who wants to practice swine medicine should be able to perform this activity without supervision

- $\quad$ Score 3 = Advanced competency: Every DVM graduate who wants to practice swine medicine should be able to explain how to perform and may have performed these tasks while being supervised.

Members of the task force were also asked to add to list any activity that was missing if it was believed to be important and critical to the practice of swine veterinary medicine. In the document they received, a comment box was left blank next to each of the activities so that they could provide any feedback if they wished to do so.

Step 3: The task force's scores and comments were compiled, analyzed, and discussed by the swine faculty in order to reach a consensus regarding which level each skill or competency belonged to. To help with the decision-making process, a $100 \%$ stacked bar chart representing the frequency of each score related to each competency was made available to the faculty members. In addition, swine faculty members considered new skills or competencies proposed by the task force and added them to the level they agreed that they were a best fit for.

Step 4: The Day-1 swine competency list was compiled by the faculty, augmented with the feedback from the practitioner task force and mapped against the CBVE framework. Each swine competency was fitted into the CBVE framework, at a level more specific than the CBVE illustrative subcompetencies. For example, the competency "Choose the appropriate needle length and gauge based on the pig age, weight, and product directions" was placed in the subcompetency 2.1.b "Performs routine therapeutic procedures (e.g., administer fluids)" and within the competency 2.1 "Performs husbandry care, veterinary procedures, and postprocedural care" in the individual care domain. At the end of this exercise, the swine faculty group identified several skills and competencies missing from their list.

Step 5: The resulting list of competencies was created as an online, interactive tool accessible by all. In this tool, the Day-1 swine competencies are grouped into nine larger domains specific to swine practice.

\section{RESULTS}

At the end of Step 1, 80 swine-related competencies were listed in a table and grouped into eight larger domains: pig handling, swine husbandry, sample collection, record keeping, treatment and prevention, biosecurity, communication, and regulatory.

Various levels of agreement were observed among reviewers. A consensus was reached for some competencies such as Write a prescription and Foot trimming as basic-level (Score 1) and advanced-level (Score 3) competencies, respectively. On the other hand, the answers were split as $33 \%$ basic (Score 1), 33\% intermediate (Score 2), and 33\% advanced (Score 3) for other competencies such as Perform a pregnancy diagnosis [Figure 3]. In this case, the University of Minnesota (UMN) swine faculty reached a consensus and decided on the level of expertise based on teaching experience. Each competency was then placed within a level of expertise as described previously (basic, intermediate, and advanced). In addition, the task force suggested an additional 14 competencies, 11 of which were added to the initial ones and assigned a level of expertise, bringing the competency list to 91 items.

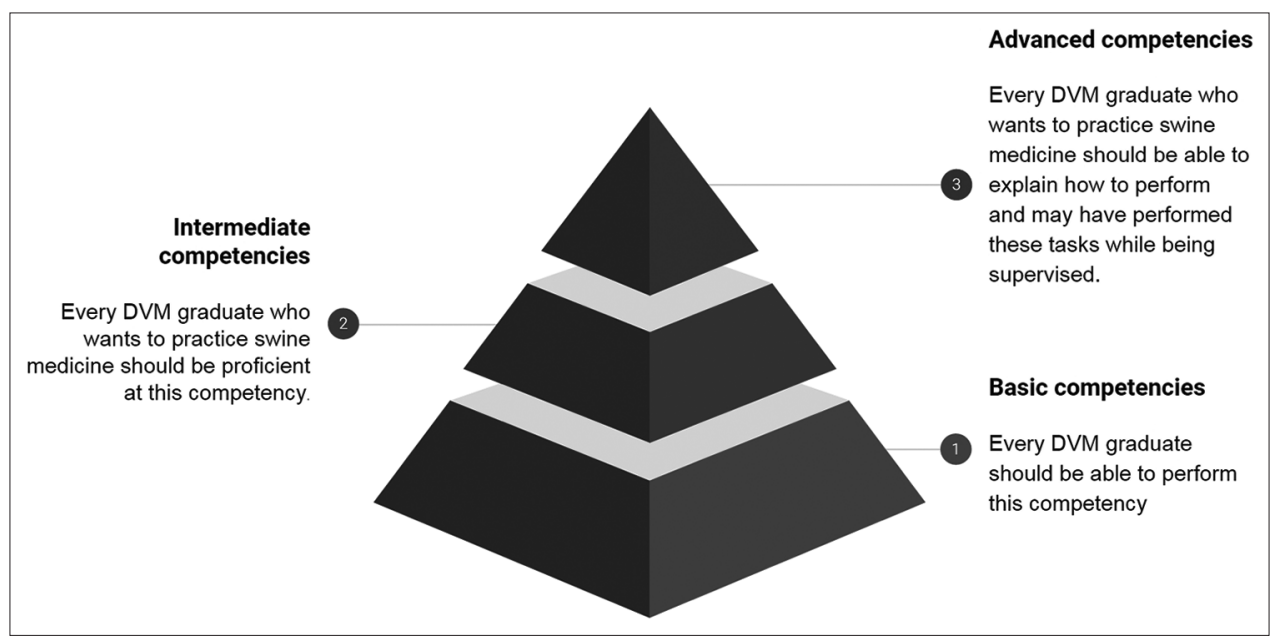

Figure 2: Representation of the three levels of expertise in the Day-1 list of swine competencies 
Zhitnitskiy, et al.: Day-1 swine veterinary competencies

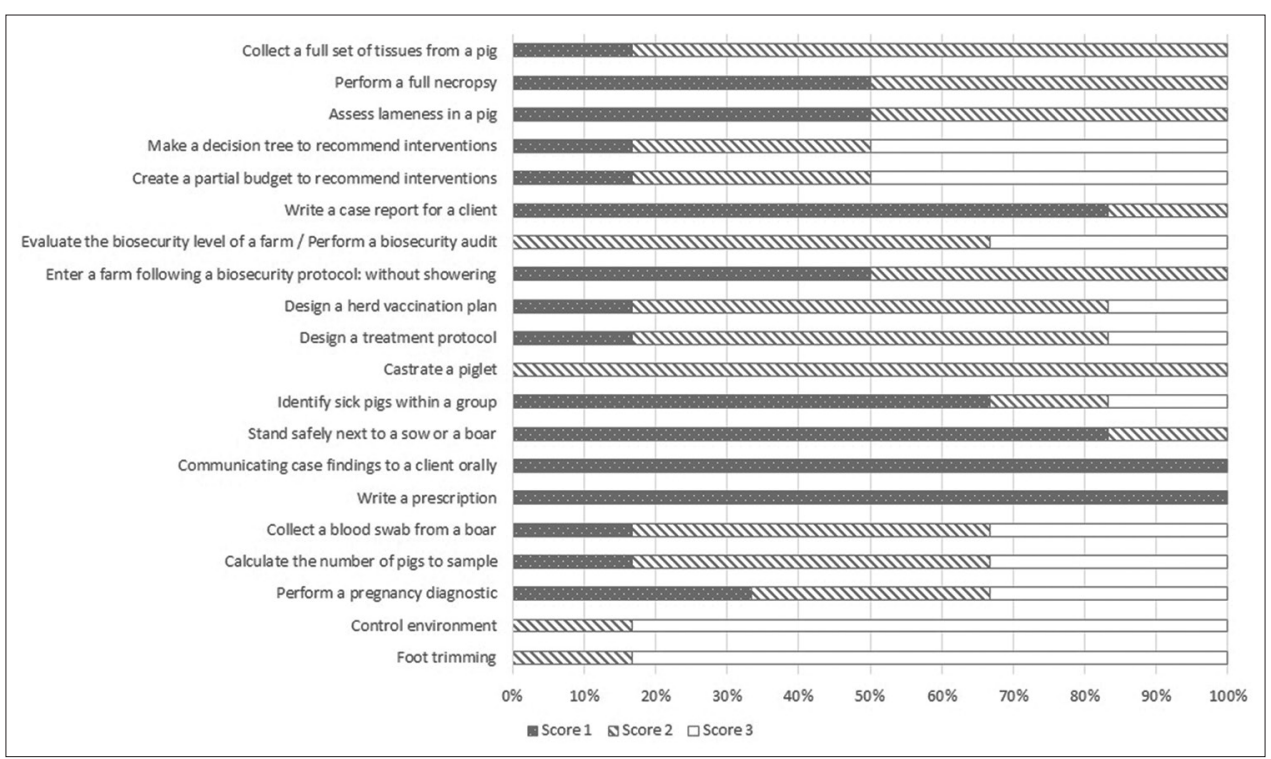

Figure 3: Task force feedback on selected representative competencies. (Score 1: Basic competency, Score 2: Intermediate competency, and Score 3: Advanced competency)

In Step 3, the CBVE framework was reviewed by the UMN swine faculty members and 18 missing competencies were identified and were added to the list for a total of 109 competencies and given a level of expertise. Not all of the added competencies were new concepts. Some items from the initial list were judged to be too vague or were synthesizing several concepts that were divided and explained in more detail in two or more updated "new" competencies. More particularly, competencies in domain 7 regarding professionalism and professional identity as well as additional details on welfare from domain 3 and biosecurity and foreign animal disease management from domain 4 were added.

The final list of Day-1 swine competencies can be found at http://z.umn.edu/SwineCompetencies.

The 109 Day-1 swine competencies were organized into nine domains: pig handling, swine husbandry, sample collection, record keeping and result interpretation, clinical reasoning, treatment and prevention, biosecurity, communication, and regulatory. The list was shared with students, faculty members, and other stakeholders at the AASV annual meeting March 2019.

\section{Discussion}

Competency frameworks can be useful to identify gaps and redundancies in curriculum content and assessments. ${ }^{[14]}$ The CBVE framework was helpful to identify missing competencies and areas of veterinary training that were overlooked during the initial two phases of the swine competency list development. The process could have been simplified if the CBVE framework had been used to map the initial list of activities when the faculty initially developed that list rather than waiting until Step 4 of the process.
The final list of swine competencies included competencies (which integrate skills, knowledge, values, and attitudes), subcompetencies, and more discreet skills. The mix of skills and competencies in the final list might have been a consequence of the introduction of the CBVE mapping later in the process. Indeed, starting the competency identification process by asking the swine faculty to think about activities that the students would be able to demonstrate was too broad. This unintended consequence shows that competency-based education supports backward design because the second question to ask faculty should have been what knowledge is required for students to be able to perform this activity. This additional question would have facilitated the differentiation between competencies and skills. Schools may find it helpful to sort the list of Day-1 swine competencies presented here into competencies, subcompetencies, and skills before incorporating them into a curriculum. The UMN CVM faculty felt that having some skills listed as part of the list was a good reminder for the students that more basic activities, usually surrounding husbandry practices in swine farms, are essential to proficient swine practice.

There was some disagreement among the task force members about whether or not some skills and competencies should be included in a list of modern Day-1 swine competencies. For example, when the list was shared with the task force, some practitioners felt that Clipping a piglet's needle teeth should not be included because this practice is not considered welfare-friendly for the piglets, ${ }^{[15]}$ and its use may be declining as a general practice within the swine industry. However, faculty members concluded that the technique would still be used in case of severe and extensive udder lesions caused by the piglets' nursing and that practitioners should be able to explain and demonstrate best practices to farm personnel. Choosing swine practitioners as experts to review the original 
list kept the skills relevant to modern swine practice. However, it is important to note that it may not be fully tailored to practitioners working with pet pigs or animals raised for shows. The size of the task force was kept small on purpose, and all the swine veterinarians involved practice in commercial settings where pigs are raised to be harvested.

The Day-1 swine competencies have been organized in three sections: basic, intermediate, and advanced with the intent that each category builds upon the previous one. Indeed, numerous intermediate activities build upon basic ones. For example, Recognize if a pig needs to be euthanized is listed as a basic activity, whereas Recommend the appropriate and approved euthanasia method based on pig age and weight, clinical situation, and employee safety is considered to be an intermediate activity. In addition to that, some of the competencies listed as basic extend beyond swine practice and can be applied to other species; Write a prescription being an example of such an activity.

The swine faculty group felt it was important to create a document in an electronic format that could be easily updated. Paper documents are not as durable; they can easily be lost or damaged. We decided that it would be advantageous for students to be able to check the competencies they felt proficient at from various locations and directly after they had the opportunity to practice, may it be after a lab in a class or after a farm visit during their preceptorships. Therefore, the list was created on the swine faculty website using a plug-in from the company Checklist.com B. V. This allows the students not only to save their progress between the $1^{\text {st }}$ year of veterinary school and graduation but also to access it with their smartphones. Indeed, the Checklist app (Checklist.com, B.V., The Netherlands) is available through smartphones or through computers. The electronic format allows the content to be updated in one central depository, and the change would be automatically in all of the students' applications, making it more advantageous than the paper format. An option to print the list of competencies is still available for learners who would feel more comfortable using a paper version.

With this project completed, it is the goal of the swine faculty to compare the developed competencies with the learning objectives of the various swine courses at the UMN CVM and to identify the domains in which the students have the possibility to practice the competencies, and the areas that the curriculum is not covering in-depth yet. Then, the faculty is planning to decide which competencies should be included in the swine curriculum and which one might be better suited for students to work on during summer internships or $4^{\text {th }}$-year externships with swine practitioners. On a broader level, the Collegiate Activities Committee from the AASV has met to discuss a core swine curriculum for DVM students, including the swine competencies list.

\section{Conclusions}

Developing Day-1 competencies for swine veterinary graduates that are practical, measurable, incorporable into a curriculum, and most importantly relevant to modern swine veterinary practice required an effort from both academic faculty and practitioners. This effort created 109 swine competencies separated in three levels of expertise related to the career paths, a DVM graduate may choose and organize in nine domains related to the various aspects of swine practice. The competencies are available at https://z.umn.edu/ SwineCompetencies. Swine faculty members are using the Day-1 competencies for swine practice to evaluate the swine curriculum at the college level with the intent to incorporate more opportunities for the students to practice and be assessed on some of the activities listed as deemed appropriate.

\section{Acknowledgments}

We would like to thank the swine faculty group at the University of Minnesota, College of Veterinary Medicine who participated in this project: Drs. Cesar Corzo, Peter Davies, Maria Pieters, and Jerry Torrison. We also would like to thank the swine task force for graciously giving their time and feedback: Drs. Glen Almond, Andrew Bents, Emily Byers, Joshua Duff, Deborah Murray, Jeremy Pittman, Alejandro Ramirez, and Brian Roggow. Finally, a great appreciation to Ms. Sue Schulteis and Mr. David Brown for their help with the AASV communication.

\section{Financial support and sponsorship}

Financial support for this study was provided from a grant from the American Association of Swine Veterinarians Foundation.

\section{Conflicts of interest}

Dr. Molgaard is a member of the Competency-Based Veterinary Education working group, but she did not receive financial compensation for her work.

\section{REFERENCES}

1. Englander R, Frank JR, Carraccio C, Sherbino J, Ross S, Snell L. Toward a shared language for competency-based medical education. Med Teach 2017;39:582-7.

2. Frank JR, Mungroo R, Ahmad Y, Wang M, De Rossi S, Horsley T. Toward a definition of competency-based education in medicine: A systematic review of published definitions. Med Teach 2010;32:631-7.

3. Welsh PJ, Jones LM, May SA, Nunn PR, Whittlestone KD, Pead MJ. Approaches to defining day-one competency: A framework for learning veterinary skills. Rev Sci Tech 2009;28:771-7.

4. Clark WT, Kane L, Arnold PK, Robertson ID. Clinical skills and knowledge used by veterinary graduates during their first year in small animal practice. Aust Vet J 2002;80:37-40.

5. Miller RB, Hardin LE, Cowart RP, Ellersieck MR. Practitioner-defined competencies required of new veterinary graduates in food animal practice. J Vet Med Educ 2004;31:347-65.

6. American Association of Equine Practitioners. Core Competencies for New Veterinary School Graduates in Equine Practice. Professional Education. American Association of Equine Practitioners; 2008. Available from: http://people.vetmed.wsu. edu/jmgay/courses/documents/AAEP Core Competencies.pdf. [Last accessed on 2019 Jan 15].

7. Frank JR, Snell LS, Cate OT, Holmboe ES, Carraccio C, Swing SR, et al. Competency-based medical education: Theory to practice. Med Teach 2010;32:638-45.

8. Carraccio C, Englander R, Van Melle E, Ten Cate O, Lockyer J, Chan MK, et al. Advancing competency-based medical education: A charter for clinician-educators. Acad Med 2016;91:645-9. 


\section{Zhitnitskiy, et al:: Day-1 swine veterinary competencies}

9. Molgaard LK, Hodgson JL, Bok HG, Chaney KP, Ilkiw JE, Matthew SM, et al. Competency-Based Veterinary Education Framework. Washington DC; 2018. Available from: https://www.aavmc.org/assets/site 18/files/ cbve-publication-1-framework.pdf. [Last accessed on 2019 Jun 16].

10. Bok HG, Jaarsma DA, Teunissen PW, van der Vleuten CP, van Beukelen P. Development and validation of a competency framework for veterinarians. J Vet Med Educ 2011;38:262-9.

11. Brown BB. Delphi Process: A Methodology Used for the Elicitation of Opinions of Experts; 1968. Available from: https://www.rand.org/pubs/ papers/P3925.html. [Last accessed on 2019 Jan 16].

12. Hubbell JA, Saville WJ, Moore RM. Frequency of activities and procedures performed in private equine practice and proficiency expected of new veterinary school graduates. J Am Vet Med Assoc 2008;232:42-6.

13. Cary JA, Farnsworth CH, Gay J, Carroll HS. Stakeholder expectations regarding the ability of new veterinary graduates to perform various diagnostic and surgical procedures. J Am Vet Med Assoc 2017;251:172-84.

14. Al-Eyd G, Achike F, Agarwal M, Atamna H, Atapattu DN, Castro L, et al. Curriculum mapping as a tool to facilitate curriculum development A new school of medicine experience. BMC Med Educ 2018;18:185.

15. Lewis E, Boyle LA, Lynch PB, Brophy P, O'Doherty JV. The effect of two teeth resection procedures on the welfare of piglets in farrowing crates. Part 1. Appl Anim Behav Sci 2005;90:233-49. 